\title{
EL TROLEO EN EL ESQUEMA \\ DE LAS PRÁCTICAS POLÍTICAS
}

\author{
RubÉn Santander HerRera* \\ Universidad de Chile \\ santanderk@ug.uchile.cl
}

Recibido: 15/12/2020 Aceptado: 26/2/2021

doi: https://doi.org/10.26439/contratexto2021.n035.5034

RESUMEN. En Chile, influyentes figuras públicas utilizan de forma creciente los medios para acusar a las redes sociales de constituir un peligro para la democracia y caracterizar a sus usuarios de intolerantes y destructivos. Este ensayo define aquella conducta, conocida como trolling o troleo, delimitando sus características constitutivas para situar el fenómeno como una práctica política independiente de la supuesta agenda de los troles, de una subcultura o de un momento histórico o tecnología específica. Para dar cuenta de la ubicuidad histórica del troleo, nos servimos de un texto periodístico de Karl Marx. A partir de la conceptualización de lo político de Rancière (2006) y de la crítica de Fraser (1999) a Habermas, sostenemos que la función del troleo es dar cuerpo a una pretensión de modificar el reparto de lo sensible mediante la imposición de nuevas oposiciones de términos, desplazando o socavando el encuadre de un discurso. En este sentido, es una práctica política potencialmente emancipatoria. El propósito de este ensayo no es valorar al troleo en términos éticos, sino situarlo con referencia a sus usos, posibilidades y relaciones, y sugerir criterios para juzgarlo como un objeto al cual es posible aproximarse desde la perspectiva de la comunicación política.

PALABRAS CLAVE: troleo / Chile / democracia / práctica política / redes sociales

\footnotetext{
* Licenciado en Antropología con mención en Antropología Física por la Universidad de Chile (véase: https:// orcid.org/0000-0003-2733-4046).
} 


\section{TROLLING IN THE FRAMEWORK OF POLITICAL PRACTICES}

ABSTRACT. In Chile, influential public figures are increasingly using the media to accuse social networks of being a danger to democracy and to characterize their users as intolerant and destructive. This essay defines that behavior, known as trolling, by delimiting its constitutive characteristics in order to situate the phenomenon as a political practice independent of an alleged trolling agenda, a particular subculture, a historical context or a specific technology. To give an account of the historical ubiquity of trolling, we used a journalistic text by Karl Marx. Based on Rancière's (2006) conceptualization of politics and Fraser's (1999) critique of Habermas, we maintain that the function of trolling is to give shape to an attempt to modify the distribution of what is sensitive by imposing new oppositions of terms, displacing or undermining the framework of a discourse. In this sense, trolling is a potentially emancipatory political practice. The purpose of this essay is not to evaluate trolling in ethical terms but to situate it regarding its uses, possibilities and relations, and to suggest criteria for judging it as an object that can be approached from the perspective of political communication.

KEYWORDS: trolling / Chile / democracy / political practice / social networks

\section{A TROLLAGEM NO ESQUEMA DA PRÁTICA POLIITICA}

RESUMO. No Chile, figuras públicas influentes estão utilizando cada vez mais os meios de comunicação social para acusar as redes sociais de serem um perigo para a democracia e para caracterizar os seus usuários como intolerantes e destrutivos. Este ensaio define esse comportamento conhecido como trolling ou trollagem, delimitando as suas características constitutivas para situar o fenómeno como uma prática política independente da suposta agenda dos trolls, de uma subcultura particular ou de um momento histórico ou tecnologia específica. Para dar conta da ubiquidade histórica da trollagem, utilizamos um texto jornalístico de Karl Marx. Da conceptualização de Rancière (2006) da crítica política e de Fraser (1999) a Habermas, defendemos que a função da trollagem é dar corpo a uma pretensão de modificar a partilha do sensível através da imposição de novas oposições de termos, deslocando ou minando o quadro de um discurso. Neste sentido, a trollagem é uma prática política potencialmente emancipatória. 0 objetivo deste ensaio não é valorizar a trollagem em termos éticos, mas colocá-lo em referência aos seus usos, possibilidades e relações, e sugerir critérios para o julgar como um objeto ao qual é possível se aproximar na perspectiva da comunicação política.

PALAVRAS-CHAVE: trollagem / Chile / democracia / prática política / redes sociais 


\section{INTRODUCCIÓN}

It is difficult to believe, but possible, that a totally normal person would become a Troll.

(Anti Troll FAQ, 2002)

Recientemente, pero cada día con mayor insistencia, un abanico muy influyente de figuras públicas ha hecho uso de su tribuna en los medios de comunicación chilenos para advertir con vehemencia algo que, viniendo de ellos, aparece como una revelación imposible de ignorar: el auténtico enemigo de la sociedad democrática no son las injusticias sociales que denuncian tantos, sino los usuarios de las redes sociales. No cualquier usuario, por supuesto, pero todos en general. Aludiendo a entelequias como "las redes", una multitud de columnistas, periodistas, investigadores de think tanks, empresarios, políticos, autoridades e incluso el presidente de la República, han llamado la atención sobre un comportamiento presuntamente ordinario al que se tilda de antisocial, antidemocrático, intolerante o destructivo. Una conducta tan peligrosa, según esta perspectiva, como para situarla al mismo nivel que, por ejemplo, las actividades de la Central Nacional de Inteligencia de la dictadura de Pinochet, como apuntaba recientemente el periodista y socio de la poderosa consultora Tironi y Asociados, Ascanio Cavallo:

Es nuevo que te vayan a gritar cosas a tu lugar de trabajo o te funen'. Bueno, no tan nuevo: también hacía eso la CNI. También te iba a funar. Dicho de otro modo: las redes sociales están cumpliendo un papel fascista. Esa es la verdad. Pequeños grupos, al modo de las montoneras, organizados para hostigar, amenazar y evitar que la gente discrepe. (Como se citó en R. Montes, 2020, p. 17)

Frente a este tipo de planteamientos, queda la impresión de que los usuarios de redes sociales conforman una especie de nueva policía secreta, altamente organizada para "evitar que la gente discrepe". Dicha caracterización no pretende aludir a los "ejércitos de troles" profesionales al estilo de los que, como se ha demostrado, usan extensamente potencias como China, India o Rusia (Howard, 2020, p. 52), sino a un rasgo propio de estas plataformas, compartido por sus usuarios regulares. Como señala Leonidas Montes (2020), director del Centro de Estudios Públicos, tradicional think tank chileno de derecha:

A ratos los comentarios y opiniones en las redes se elevan hacia un ethos que desprecia las reglas más básicas de la razón, la moral y la prudencia. [...] El verdadero peligro para una sociedad liberal no es la epidemia. Es el dogmatismo de los que se creen dueños de la verdad y rasgan vestiduras con su propia moral subjetiva. (p. 3)

1 Funa es el nombre que se da en Chile a las manifestaciones de repudio público. La discusión en torno a la funa tiene en Chile las mismas connotaciones que la referida a la llamada cancel culture en otros países. 
No se denuncia una actividad propagandística específica, como el astroturfing que el mercado de las llamadas "fábricas de troles" ha puesto al alcance de intereses políticos alrededor del mundo (Keller et al., 2017; Kovic et al., 2018; Linvill y Warren, 2020). La preocupación está puesta sobre la comunicación regular en redes sociales y sobre la naturaleza misma de sus usuarios:

Veamos los síntomas más severos de esta enfermedad letal para la convivencia: se banalizan formas de comunicación degradatorias (como las que imperan en las redes sociales), se lincha y se demoniza a los adversarios, se denuesta al que ose pensar distinto. (Warnken, 2020, p. 3)

Este llamado al "pánico moral" que busca dibujar un estereotipo de los usuarios de redes sociales ha sido descrito en otros contextos (Bishop, 2014). Pareciera que para estos comentaristas la conducta general de los individuos en internet confirmara y actualizara ese mito que origina nuestro mundo: ahora el hombre es el trol del hombre. El troleo transmuta en estas lecturas desde su concepción analógica original (alguien que ejecuta una acción específica: practicar trolling, pescar con cebo) a una nueva y difundida función alegórica: el trol como ser mitológico, humanoide monstruoso y antisocial.

Lo que estos comentaristas insinúan con estridencia es que las redes sociales son un espacio yermo de racionalidad política. Pero a la vez plantean que ese tránsito interminable de mensajes irracionales, inmorales e imprudentes constituyen un riesgo para nuestra democracia. Aquello que busca anular el disenso y la "sana deliberación" democrática (el fascismo de las redes que denuncia Cavallo) es el statu quo instituido en los foros y plataformas sociales. Un orden dado que excluye al que piense distinto, ¿pero distinto de qué? No lo sabemos. Estaríamos frente a un dogmatismo cuya irracionalidad y exacerbada subjetividad lo hacen incomprensible. Como los alaridos de un trol, que solo un demente podría confundir con lenguaje. Esta atribución de ininteligibilidad es una manera de descartar cualquier pretensión política: "A quien no queremos conocer como ser político, comenzamos por no verlo como portador de signos de politicidad, por no comprender lo que dice, por no entender que es un discurso que sale de su boca" (Rancière, 2006, p. 72).

Siguiendo a Rancière (2006, 2011), es el litigio político lo que hace existir la política (la igualdad) y lo que la separa de la policía, la ordenación del cuerpo social bajo la autoridad de una competencia que distribuye lugares y funciones. Para los comentaristas que hemos citado, la policía es la masa de usuarios, mientras que personas como ellos, autodenominados librepensadores, son la política misma, la ley de la igualdad. Curiosa inversión de los términos.

La policía constantemente busca desaparecer el litigio y, por tanto, la política. Este proceso tiene dos vectores posibles y ambos pueden ser reconocidos en el discurso de los comentaristas aludidos. Por un lado, la negación de la especificidad del troleo al 
confundirlo con otros procedimientos y al rechazarlo como práctica política, es decir, como litigio. Por otro, la identificación de la lógica de la política como la suya propia, mediante la apropiación de la racionalidad de cualquier disenso posible en el espacio de comunicación virtual, al someterlo a unas reglas ambiguas en torno a las virtudes de la mesura, la prudencia, el buen gusto y lo apropiado. Presentarse como una actualización de lo propio de la comunidad y transformar las reglas del gobierno en leyes naturales de la sociedad es lo propio de la policía, mientras que la política discurre mediante la verificación de la igualdad de cualquier ser hablante con cualquier otro. El discurso de los comentaristas mencionados no se sitúa en la política, por más que pretendan aparentarlo. Ellos niegan la mera posibilidad de un litigio en el reparto de lo sensible.

Argumentaremos en este ensayo a favor de situar al troleo como una práctica dentro del esquema de la política, con la intención de aproximarnos a su sentido, a su racionalidad, y de entender de qué forma "las redes" y sus estrategias comunicativas ponen o no en riesgo la democracia, como se denuncia con frecuencia. Pero antes de continuar es preciso delimitar de forma más detallada el fenómeno en que nos concentraremos, el troleo, con el objetivo de encontrar aquello que le es constitutivo, sobre todo atendiendo a la variedad de las conductas en el contexto digital y a sus aparentemente rápidas transformaciones. Posteriormente, presentaremos los argumentos que nos permitirán disociar al troleo como práctica política de unas ciertas condiciones técnicas e históricas. Finalmente, habiendo delimitado de esta forma el fenómeno, nos enfocaremos en comprender su racionalidad y cómo se inserta en el esquema de las prácticas políticas.

\section{TROLEO: TRAS UNA DEFINICIÓN OPERATIVA}

Troll y trolling son términos que han sido usados (en un sentido similar o solapado con el actual) al menos desde comienzos de la década de 1990 (su aplicación se remonta a los foros de BBS y Usenet, predecesores de internet). Desde entonces, ha sido vastamente tratado por el periodismo de tecnología, al mismo tiempo que, como categoría de análisis, su uso se ha concentrado principalmente en la ciencia de datos y, en el ámbito de las ciencias sociales, fundamentalmente en estudios sobre la cultura en línea. De esa forma, mientras que hacia fines de la década de 1990 revistas como Wired hablaban cotidianamente de los trolls, cada foro de la World Wide Web contaba con una política específica para hacerles frente. Los investigadores de la sociedad solían pasar por alto el concepto o concentrarse en una caracterización del fenómeno notablemente influida por textos pioneros como Communities in cyberspace (Smith y Kollock, 1999), donde es definido como "un juego de engaño de identidad" fuertemente atado a un contexto sociotécnico específico.

La situación al día de hoy no ha cambiado radicalmente: pese a su ubicuidad, aparentemente se trata de un fenómeno (o quizá, varios fenómenos) demasiado plástico como 
para poder constituirse como un elemento demasiado útil para el análisis. Así, muchas veces el término es usado simplemente como una forma despectiva de agrupar varios comportamientos en línea, especialmente aquellos disruptivos. Por ejemplo, Shaffer (2019) define a los troles como "acosadores, abusadores y otros tipos de actores negativos, que normalmente operan a la vista", equiparando el troleo al ciberacoso. Calvo y Aruguete (2020) describen al trol como un actor cuyo objetivo "es callar a su oponente y evitar que el mensaje del 'otro' siga circulando por la red" y optan por no hacer una distinción entre troles, cuentas falsas y redes de astroturfing. Por su parte, Kovic et al. (2018) resaltan la importancia de no mezclar los conceptos de trolling y astroturfing, limitando la caracterización del primero a "un comportamiento malicioso, perturbador o desinhibido" y destacando que es llevado a cabo por individuos motivados por su propia voluntad, a diferencia del astroturfing, que estaría propiciado por actores políticos. Kovic et al. (2018) no descartan el rol político del troleo, pero tampoco se refieren a sus posibilidades.

Muchas descripciones del troleo han sido desarrolladas en el marco de estudios de comunidades de internet comprendidas como subculturas (Coleman, 2012; Phillips, 2015). Este tipo de trabajo suele poner énfasis en el aspecto "irreverente" de los troles y sus motivaciones en términos de su propia diversión ("Lulz"). Coleman (2012) basa su análisis y extrapola su definición del troleo principalmente en una fuente temprana, pero limitada, la Encyclopedia Dramatica², escrita por un grupo no necesariamente representativo de la complejidad de internet. Trabajos como este y el de Phillips (2015) se concentran en conjuntos idiosincráticos de internet más o menos discretos y en gran medida en los efectos que el troleo produce en los propios troles. En su libro The dark net (2016), el periodista británico Jamie Bartlett también considera a los troles como parte de una subcultura de internet, apuntando a un cierto tipo de usuario especializado en perturbar las conversaciones de sitios como 4chan o Reddit. Bartlett no realiza una caracterización del comportamiento mismo, sino de la cultura a la que asocia a sus informantes.

Ya que nuestro objetivo es indagar si estas formas de comunicación ponen en riesgo algunos aspectos de la sociedad, nuestro interés aquí se centra en el efecto que el troleo produce en la comunicación misma. Para esto procuraremos establecer una definición general de la actividad en cuanto tal, no vinculada a una cultura específica, ni a una comunidad, ni a un sitio o plataforma de internet en particular. Uno de los primeros intentos de ofrecer una definición operativa del fenómeno en estos términos en el ámbito académico

2 La Encyclopedia Dramatica fue un sitio web en formato wiki lanzado en diciembre del 2004 que recopilaba temas relevantes para la cultura de internet. Sus artículos documentaban bromas, memes, "raids", troleos masivos, fallas de seguridad y otros eventos, y se caracterizaba por su contenido NSFW, misógino, homofóbico y racista. Sus participantes sostenían una idea militante del trolling como ofender la sensibilidad de otros (Encyclopedia Dramatica, s. f.). 
es el de Hardaker (2010), cuya aproximación se centra en sus efectos psicosociales: el trol como un usuario que se incorpora a una comunidad transmitiendo intenciones "pseudosinceras", pero cuyo objetivo es desencadenar o exacerbar el conflicto. Lo esencial de esta definición es el componente de manipulación asociado al troleo. Dicho componente se encuentra en el propio origen del término.

En inglés, trolling significa literalmente "pescar arrastrando un señuelo o un anzuelo con cebo desde un barco en movimiento" (Merriam-Webster, s. f., definición 1). El sentido de la expresión aplicada a un tipo de comportamiento en los foros de internet aparentemente pretendía ser una analogía a la pesca con cebo (Donath, 1999, p. 54). El troleo, en su formulación original, consiste en inmiscuirse deliberadamente en una conversación haciendo comentarios irrelevantes, incendiarios u ofensivos con el fin de llamar la atención de otros, arrastrarlos a una discusión, cambiar el tema o burlarse. Se trata de una excelente analogía: solo da cuenta del fenómeno, sin descartar el componente de manipulación que han destacado investigadoras como Hardaker (2010) y Donath (1999), pero sin detenerse en aquellos aspectos psicológicos que son difíciles o imposibles de observar (como las motivaciones no manifiestas del trol) y sin remitirse a una comunidad en particular.

Mylonas y Kompatsiaris (2019) aportan una perspectiva en esta línea al escindir su análisis de un determinado grupo de usuarios de internet y entender "su potencial como forma de política cultural que puede informar sobre los desafíos contrahegemónicos de las ideologías predominantes" (p. 2). Entenderemos al trol como un provocador, cuya participación en foros y discusiones de redes sociales se caracteriza, ya sea por un cierto grado de violencia verbal, por constituirse en un elemento distractivo o fuera de tema, por banalizar un tema que los demás integrantes de una conversación consideran serio, o por "enseriar" un tema que los demás integrantes de una conversación consideran trivial. No es poco importante la frecuencia con que esta forma de interactuar pretende ser cómica, irónica o satírica: es común que el trol arrastre a otros al troleo contra un usuario o grupo usando la burla o la humillación. Si bien autores como Mylonas y Kompatsiaris (2019) se concentran en lo que podríamos llamar el resultado proselitista de la transgresión en la que incurren los troles, aquí propondremos que esta por sí misma tiene unos efectos que sobrepasan dicho aspecto.

Lo constitutivo de la conducta de un trol es su afán por molestar a su interlocutor o interlocutores, en última instancia, arrancar de ellos alguna clase de respuesta emocional y, en un determinado plazo, corromper o destruir las bases discursivas de una conversación o forzar un cambio en los fundamentos mismos del debate. En este sentido, su efecto no sería solamente la denuncia del funcionamiento oculto de los discursos hegemónicos (Mylonas y Kompatsiaris, 2019, p. 53), sino que podría conducir a entablar un litigio en el reparto de lo sensible. 
Debe distinguirse el troleo, práctica generalizada a la que referiremos en este trabajo, tanto de sus configuraciones y adaptaciones a nichos específicos (como las actividades descritas por Bartlett en los hilos de 4chan) como de sus derivaciones posteriores. El troleo hoy es una práctica difusa, usada tanto por usuarios "orgánicos", guiados por sus propios motivos, como - y de forma creciente- por organizaciones (las llamadas granjas, fábricas o ejércitos de troles) que ejecutan operaciones coordinadas de intervención comunicacional o astroturfing a través de cuentas falsas en redes sociales a cambio de dinero. Como han señalado Kovic et al. (2018), se trata de fenómenos entre los cuales es importante establecer claras distinciones. Podríamos ver a las granjas de troles como el desarrollo del fenómeno a una escala industrial y, aunque estos "troles" pueden usar en algunos casos el mismo tipo de procedimientos que los troles orgánicos, su objetivo primordial es difundir a través de numerosas cuentas falsas rumores o información incorrecta o tendenciosa, buscando alterar la opinión pública en favor de algún actor político. Una forma más precisa de referirse a estos actores podría ser el término sock puppets, cuentas falsas controladas por humanos (Bu et al., 2013).

Las advertencias vehementes contra la "enfermedad" o comportamiento "fanático" que según algunos recorre las redes sociales aparentemente no pretenden poner fin a las actividades de las fábricas de troles, de las que muchos políticos y gobiernos se sirven, sino denunciar a los que llamaremos "troles orgánicos", aquellos que actúan por propia motivación y comúnmente, aunque no exclusivamente, de forma no coordinada con otros.

Esta distinción entre troles orgánicos y troles artificiales (sock puppets cuyas actividades de astroturfing toman la forma de troleo) nos permite apreciar que el troleo es una táctica o estrategia, no una condición ni un rasgo de personalidad. Tampoco un aspecto exclusivo de una subcultura ni, necesariamente, un pasatiempo u ocupación. El troleo puede formar parte del repertorio habitual de una persona contratada para inmiscuirse de forma anónima en un determinado contexto de comunicación (un sock puppet), como puede ser un recurso usado de vez en cuando por un usuario "real", con nombre y apellido. Cualquier usuario regular de redes sociales puede ser y probablemente ha sido un trol. Asimismo, cualquier usuario regular sabe reconocer un trol y la mayoría sabe (y debe) lidiar con ellos día a día. Lo significativo es la conducta de trolear y no una identidad en cuanto trol.

Hecha esta distinción, cabe preguntarse si el troleo surge dadas ciertas condiciones inéditas que propician internet y las redes sociales. ¿Se trata de un fenómeno nuevo, como parece desprenderse tanto de los esfuerzos por caracterizarlo que hemos mencionado (concentrados en el ámbito de las subculturas de internet) como de los comentarios de pánico moral a los que hemos aludido al inicio de este ensayo? ¿0, por el contrario, presenta parentesco o identidad con otras actividades humanas preexistentes? 


\section{PARA UNA PERSPECTIVA HISTÓRICA DEL TROLEO}

$\mathrm{Si}$ atendemos a los frecuentes comentarios acerca de los comportamientos de los troles en internet, queda la impresión de que estamos en presencia de un fenómeno relativamente nuevo y que supuestamente emerge bajo ciertas condiciones que propician las plataformas sociales de internet: anonimato, impunidad, libre expresión, confidencialidad. Aquí disputaremos dos cosas: primero, proponemos que los troles y el troleo, por una parte, no constituyen un asunto completamente novedoso y que, atendiendo a la caracterización que hemos realizado en la sección anterior, en líneas generales se trata de un comportamiento que precede a la creación de internet, sus foros y sus normas (o ausencia de ellas). En segundo lugar, afirmamos que hoy no existe tal cosa como el anonimato y la impunidad de las personas en internet y que está muy en duda la preeminencia de la libertad de expresión en dicho contexto.

Para afrontar el segundo tema haría falta mucho más espacio del que disponemos, pero señalaremos solo dos hechos: hoy en día los organismos de inteligencias y las brigadas especializadas de las policías de diferentes países no tienen ningún problema en dar con el paradero preciso de usuarios regulares de redes sociales, aunque estos no publiquen su nombre, foto ni otros datos personales en sus perfiles. Por señalar un ejemplo reciente en el contexto chileno en el que hemos situado este texto, el caso del usuario anónimo de Twitter identificado como @nortinaswar es revelador de cómo la ilusión de anonimato en las redes sociales es fácilmente impugnable. El 16 de agosto del 2018, este usuario publicó un breve mensaje relacionado con la entonces ministra de Secretaría General del Gobierno de Chile: "Soñé que era del MIR ${ }^{3}$ y me joteaba ${ }^{4}$ a Cecilia Pérez para poner una bomba en su casa". Tres días después de la publicación, el 19 de agosto, la policía detuvo al autor del tuit en su residencia (Romero, 2018). Es innegable que las plataformas que usamos para comunicarnos en internet están intervenidas por muchos métodos y, a menos que se haga un esfuerzo técnico especial para proteger la propia identidad (lo que no está al alcance de cualquier usuario), no existen el anonimato ni la impunidad.

La libertad de expresión en internet, por otro lado, actualmente se encuentra seriamente amenazada. En naciones como China, Turquía, Rusia y otras, la censura en internet está institucionalizada. Según Roth (2020), hoy China constituye la mayor amenaza global a los derechos humanos, entre otros factores, por la extendida censura que impone el gobierno sobre internet y el uso extensivo que hace de las nuevas tecnologías para configurar un Estado de vigilancia irrestricta.

3 Movimiento de Izquierda Revolucionario, organización política chilena de orientación marxistaleninista.

4 En Chile y en este contexto, la expresión jotear significa seducir o cortejar. 
Pero aquí nos concentraremos sobre todo en el tema de la presunta novedad del fenómeno. Mientras más cerca de los "orígenes" del troleo se ubican las investigadoras e investigadores, parece resultarles más sencillo verlo como la continuidad de estrategias comunicacionales preexistentes. Así, Donath (1999), que considera el troleo como un "juego de engaño de identidad", para dar cuenta de este comportamiento se apoya en el trabajo de Goffman, que en The presentation of self in everyday life (1959) busca, a partir de la metáfora de la performance teatral, entregar una perspectiva de aquella vida social que se organiza dentro un espacio físico delimitado. En el trabajo de Donath (1999), este espacio delimitado serían los grupos de Usenet.

Pese a que este ensayo no tiene por objetivo desarrollar una historia del fenómeno, demostrar que el troleo no es algo dependiente de internet y las redes sociales, sino que precede a unas condiciones sociotécnicas determinadas, nos puede dar un mejor entendimiento de su carácter como práctica política independiente de un medio y de una tecnología. Asimismo, nos permitirá situarlo mejor respecto a otras actividades humanas. Como señala Papacharissi (2005), la distinción entre lo online y lo offline, la vida real en oposición a lo que sea que sea aquello que pasa en internet, no parece especialmente útil en términos analíticos. Para introducir una perspectiva del troleo que nos permita concebirlo como una práctica independiente de internet, rescataremos un momento poco conocido pero muy ilustrativo de la vida de Karl Marx como polemista político.

\section{MARX, EL TROL}

El 26 de julio de 1844, Heinrich Ludwig Tschech disparó dos tiros contra el rey Federico Guillermo IV de Prusia. Un entusiasmo patriótico recorrió Berlín tras propagarse la noticia de que el monarca había resultado ileso. Al reflexionar sobre la tentativa de magnicidio, a Jenny von Westphalen le llamó la atención su móvil: el autor había actuado bajo el impulso de la desesperación y el hambre, no por una motivación política. "Si un día [la revolución] llega a estallar, estallará por ese lado. Es el punto más sensible, es ahí donde el corazón alemán es más vulnerable" (Terradas Saborit, 1992, p. 64), razona Jenny en una carta dirigida a su esposo. Pero el joven Karl Marx, a diferencia de ella, opta por concentrarse en un aspecto algo más pedestre del episodio.

Tras el atentado, el 5 de agosto de 1844, justo antes de partir de vacaciones, Federico Guillermo IV manda publicar un mensaje dirigido a sus vasallos que inicia así:

No puedo abandonar el suelo de la Patria, ni siquiera por un corto tiempo, sin expresar públicamente la profunda gratitud en el nombre de Mí y el de la Reina, que ha hecho que Nuestro corazón se conmueva. Ha sido producto de innumerables muestras verbales y escritas de amor por Nosotros que el atentado del 26 de julio evocó - el amor que nos sacudió jubilosamente en el mismo momento del 
crimen, cuando la mano del Todopoderoso desvió el proyectil mortal lejos de Mi pecho al suelo. (Como se citó en Marx, 1844)

Desde su exilio en París, Karl Marx, súbdito de Federico Guillermo IV, leyó estas palabras con divertida consternación. Tratándose de un monarca cuyos apologistas llamaban el Rey Romántico (Romantiker auf dem Thron, como se indica en Friedrich Wilhelm IV, s. f.) por hacerse rodear de humanistas e intelectuales, la deficiente sintaxis de su mensaje era un acicate difícil de ignorar para un adversario. La réplica de Marx, titulada "Ilustraciones sobre un reciente ejercicio estilístico de Federico Guillermo IV", fue publicada el 17 de agosto de 1844 en el periódico Vorwärts!, un panfleto de izquierda para lectores alemanes avecindados en París, con un tiraje de unos cuantos cientos de copias. Expondremos brevemente el tono de esta publicación, ya que constituye un perfecto ejemplo de troleo.

"La emoción inmediata es un mal escritor", argumenta Marx (1844) en su escrito. "La carta que un amante escribe al objeto de su amor en un momento de gran excitación no es un modelo de estilo", señala. Por lo tanto, la "apasionada falta de claridad y errática confusión" que se advierte en el mensaje del rey solo demuestran "la profunda sinceridad de la gratitud del Rey más allá de toda duda". Continúa Marx:

Por la construcción de la oración inicial, podría pensarse a primera vista que los corazones reales fueron conmovidos por sus propios nombres. Si el asombro ante esta peculiar emoción lo hace a uno volver a pensarlo, se manifiesta que la conjunción relativa "que ha hecho que Nuestro corazón se conmueva" se refiere no al nombre, sino a la gratitud, más remotamente situada.

El uso del singular "Nuestro corazón" que hace Federico Guillermo IV al referirse a dos corazones, el de la reina y el suyo, "puede ser justificado como una licencia poética, una cordial expresión de la cordial unidad de la cordial pareja real". Respecto a la decisión de su majestad de referirse a sí mismo en tercera persona ("en el nombre de Mí y el de la Reina"), Marx considera que "es un privilegio de grandes hombres y de los niños hacer que su nombre sea el sujeto de la oración".

Así Marx sigue burlándose, por un trecho, de las capacidades e intenciones del rey de Prusia, trivializando de paso tanto el atentado como la suerte del monarca y el entusiasmo patriótico que había despertado entre sus partidarios. Todo esto fue, desde luego, un pequeño solaz para un Marx de 26 años, antes de proseguir con proyectos más ambiciosos. Pero el troleo ejecutado desde su pequeña tribuna anónima ubicada a una distancia que parecía asegurar la impunidad llegó a oídos de Federico Guillermo IV y provocó la reacción emocional esperada por el trol, aunque la respuesta fue un poco más intensa que lo que Marx hubiera deseado. El 7 de enero de 1845, un enviado prusiano se presentó en la corte del rey francés Luis Felipe: según comenta Wheen (2018), se trataba nada menos que del connotado naturalista Alexander von Humboldt. 
Dos semanas después de la visita, la autoridad de París ordenó la expulsión de Karl Marx del territorio francés y el cierre permanente de la insolente revista Vorwärts!

Esta anécdota ilustra, de forma un tanto amplificada, la precedencia del troleo a los foros y redes sociales de internet. Al hacer esta afirmación, conviene discutir la diferencia que existe entre la sátira y lo que llamamos troleo. La sátira es ante todo un género literario en el que se censuran los vicios, la torpeza o los abusos humanos por diferentes métodos retóricos, como la ironía, el ridículo o la parodia (Elliott, 2019). Sin duda puede servirse de los elementos con que aquí hemos caracterizado al troleo, pero que no se agota en ellos. La sátira es inteligente; el troleo puede serlo, pero no necesita serlo. En el troleo, el subtexto - que es central para la sátira- no es tan importante como el efecto en el adversario. La sátira, a diferencia del troleo, no precisa que el adversario "muerda el anzuelo" para ser exitosa, sino que depende del ingenio y del estilo. Como señalan Mylonas y Kompatsiaris (2019, p. 37), el trol busca engañar al adversario respecto a sus verdaderas intenciones, la sátira no, o no necesariamente. Si bien el texto de Marx persigue ridiculizar al oponente como haría una sátira, no solo logra eso: al conducirlo a una respuesta emocional, consigue desplazar los términos en que está planteada la discusión.

Así, el texto de Marx puede ser descrito como sátira en cuanto a su género literario y a la vez como un troleo en términos de sus efectos comunicativos. Pero no toda sátira es troleo. En este caso, se ajusta a la caracterización del troleo que hemos delineado más arriba: inmiscuirse o responder una comunicación mediante comentarios irrelevantes, incendiarios u ofensivos, a través de elementos distractivos o fuera de tema, trivializando algo que otros consideran serio o importante, interactuando con la pretensión de arrastrar al adversario a una reacción o discusión fuera del marco del discurso. La respuesta emocional del contrincante es el triunfo del trol.

Sumemos a esta definición los elementos que según los críticos de "las redes", como los que hemos citado al inicio de este ensayo, son propios y originales de internet y constitutivos de estas supuestas nuevas "formas de comunicación degradatorias": el presunto anonimato, la confianza en la impunidad, la posibilidad de la libertad de expresión. Y también: la facilidad de difundir una opinión pública o entablar un diálogo con otros actores sociales que ofrece el acceso democrático a determinados medios técnicos. Como vemos, son todos supuestos aplicables a las condiciones en torno a la breve editorial escrita por Marx en Vorwärts!

No se propone aquí que Marx creyera en la realidad de estas condiciones, como tampoco asumiremos que los troles orgánicos actuales sean por definición tan ingenuos como para confiar ciegamente en ellas y que, bajo el estímulo de esa creencia, actúen en la forma que lo hacen. Lo que se propone es que un comentarista conservador 
y tecnófobo podría alegar que las comunicaciones llenas de "odio" y sorna, que tanto Marx como los troles de hoy son capaces de ejecutar para "demonizar a los adversarios", son propias o incluso exclusivas de unas condiciones materiales y epocales de degradación, una condición degenerada de lo social. Que no son una estrategia, acción dirigida a un fin o una práctica política. Cualquiera de los comentarios citados al inicio de este ensayo podría haber sido aplicado por los partidarios de Federico Guillermo IV a la breve columna escrita por Marx.

Frente a la oportunidad que se le ofrecía, Marx pudo haber defendido al perpetrador del atentado o concentrarse en sus motivos y así, desde esa perspectiva, atacar a su adversario político. También podría haber discurrido sobre la conveniencia o no de la violencia política. En cualquier caso, hubiera sido una actitud enmarcada dentro de la conversación que el monarca pretendía establecer al usar el lenguaje del "amor" en oposición al "crimen", de la "Patria" en oposición a "nuestros" enemigos, del bien contra el mal. Como en otras ocasiones, Marx podría haber seguido el camino de la crítica. La tarea primordial de cualquier crítica, señala Butler (2002) al interpretar a Foucault, es poner en relieve el marco de evaluación. La del trol es, mediante una operación de engaño, ocultarlo y desplazarlo. Marx optó por el camino del troleo: humillar a su adversario por motivos ajenos al marco de la conversación y provocar una reacción emocional que transforme las reglas del debate. Como troleo, la réplica de Marx a la nota de agradecimiento del rey fue totalmente exitosa: logró que Federico Guillermo IV mordiera el cebo y provocó una reacción que, junto con hacerlo admitir todos los cuestionamientos a su intelecto que deslizaba el escrito, lo mostraron como el ruin déspota que Marx consideraba que era.

\section{CÓMO SE INSERTA EL TROLEO EN UN ESPACIO DE DELIBERACIÓN PÚBLICA}

El ejemplo tomado de la vida de Marx como activista político y polemista tiene la pretensión de desprender al troleo de internet, sus foros y sus plataformas sociales, para situarlo en el esquema de lo político, como una práctica política potencialmente inserta en un espacio público.

Hemos definido al troleo como una práctica, porque su comprensión en cuanto actividad depende de su inscripción en una racionalidad propia preconfigurada (Estrada Saavedra, 2003), en un lenguaje que los participantes dominan para relacionarse con sus (supuestos) pares. Como muestra nuestro ejemplo, pero como también han delineado otros autores al analizar diferentes formas de troleo en línea (Mylonas y Kompatsiaris, 2019; Zelenkauskaite y Niezgoda, 2017), esta práctica puede ser ubicada dentro de lo político, entendido como el espacio donde se ponen de manifiesto las relaciones de poder entre gobernados y gobernantes 0 , en palabras de Rancière (2006), entre dos procesos 
heterogéneos: el gobierno (la policía) y la igualdad (la emancipación). Cuando adquiere esta configuración, el troleo puede ser estudiado como una práctica política. Entendemos como práctica política una disciplina ${ }^{5}$ de acción que permite entablar un litigio.

Así, el troleo es una práctica política cuando su función es posicionar en la esfera pública, en el sentido de escenarios de discurso público (Habermas et al., 1974), de interacción discursiva, de litigio y de dar cuerpo a una pretensión de modificar el reparto de lo sensible mediante una actualizada distinción entre amigo y enemigo. La provocación y la manipulación que caracterizan al troleo tienen por principal objetivo generar una respuesta emocional en el adversario que, al delatar intenciones, temperamentos o ideas que pretendían permanecer bajo la superficie, permita imponer nuevas oposiciones de términos para el litigio, desplazando, cambiando o socavando el encuadre de un discurso. Un troleo político efectivo es capaz de conducir a un adversario desprevenido a un terreno discursivo para el que no estaba preparado, a un espacio de deliberación impredecible, cuyas reglas no están completamente preestablecidas por la policía. Un espacio igualitario.

La caracterización que hemos hecho del troleo, incluyendo el ejemplo tomado de la biografía de Marx, es la de una racionalidad susceptible de tener un rol político en un espacio público. Pero ¿se corresponde el espacio generalizado de las plataformas sociales y foros de internet con una esfera pública, es decir, con un escenario de la vida social donde se puede conformar opinión pública? Este es un problema central cuya resolución escapa a las pretensiones del presente trabajo. Sin embargo, podemos señalar algunos elementos que nos parecen relevantes para entender la inserción del troleo, en el sentido que le hemos dado, en el contexto de las plataformas sociales de internet.

Por un lado, es difícil negar que se trata de un espacio que al menos ofrece la posibilidad del encuentro de sujetos comprometidos en una discusión racional sobre lo público. Sin embargo, como apunta Fraser (1999), Habermas presupone que la esfera pública es un espacio homogéneo 0 , al menos, uno donde los interlocutores pueden poner a un lado sus diferencias de estatus para deliberar como iguales. Asimismo, considera que este espacio presupone la ausencia de coacción (Habermas et al., 1974). Aunque podríamos pensar que quizá internet promete algo más parecido a esta dimensión, que Fraser (1999) caracteriza como un "espacio de cero grados en lo cultural", sabemos que dicha promesa no se realiza. Además de ofrecer barreras de acceso y distribución de

5 Es una "estrategia" según el uso que Certeau (2013) le da al concepto: un cálculo de relaciones de fuerza que permite a un sujeto asumir una posición de lo propio que sirva de base para entablar relaciones con un otro y cuya síntesis toma la forma de un discurso. Pero simultáneamente este cálculo no es propio de un sujeto de poder y es dependiente del tiempo, de la capacidad de aprovechar "al vuelo" las oportunidades que se presenten, y en ese sentido se corresponde con una "táctica". Para evidenciar esta condición intermedia, proponemos el uso de la palabra estratagema, cuyo significado es un ardid o engaño artificioso temporalmente situado dentro de una batalla, pero que está hilvanado a un esquema de acciones estratégicas que reconocen un adversario. 
todo orden, para considerar las plataformas sociales como un espacio público "neutro" habría que omitir que hay condiciones que preceden a lo político (y que afectan la autonomía de los sujetos) y actores a los que históricamente se les ha negado el principio de igualdad y su consecuencia. Internet no logra que las desigualdades sociales sistémicas sean eliminadas; simplemente es capaz de ocultarlas con más fuerza, de forma tal vez más impenetrable.

No obstante, es posible que esta fantasía sobre las bondades de una red igualitarista, donde todas las personas supuestamente parten de cero y operan bajo las mismas condiciones (se presume que nada nos obliga a delatar nuestro género ni la forma en que pronunciamos una lengua en particular, por ejemplo), constituya un escenario que permita que los individuos tomen posición frente a la posibilidad de personificar una visión utópica de la esfera pública y, por esa vía, ante la posibilidad de su propia subjetivación.

Si existe esta esfera pública en las plataformas sociales, aunque sea limitada o un mero teatro de deliberación, en la práctica se ofrece efectivamente para la proliferación de una multiplicidad de públicos con diferentes agendas y la posibilidad de su encuentro discursivo. Esto, desde la perspectiva de Habermas, señala Fraser (1999), constituiría un alejamiento de la democracia, no un acercamiento: siempre será preferible para la conceptualización del espacio público burgués una configuración homogénea, cuyo discurso se restrinja exclusivamente al bien común y no a posicionamientos particulares. En cambio, las plataformas sociales parecen un lugar privilegiado para la manifestación y construcción de públicos alternativos, contrapúblicos en el lenguaje de Fraser, que escenifican discursos paralelos al del "bien común". Estos públicos se caracterizan por formular interpretaciones oposicionales de sus identidades e inventan nuevos términos para describir realidades sociales excluidas. Oponen lógicas que cuentan de modo diferente las partes de la comunidad, podríamos decir con Rancière (2006).

Al encuadrar el litigio en nuevas oposiciones de términos, es posible disputar el reparto de lo sensible. Sin embargo, para hacer ese reencuadre, es necesario desplazar al adversario político a una nueva arena discursiva. Una forma de lograrlo es a través de la práctica que denominamos troleo.

Como señala Fraser (1999), los contrapúblicos capaces de generar estas nuevas oposiciones también pueden ser explícitamente antidemocráticos y antigualitarios. El troleo es una estratagema a disposición de cualquiera, pero parece ser que como práctica política coordinada no ha sido disputada por la izquierda democrática, pese a que su uso por activistas orgánicos es frecuente. En contraste, existen indicios que tanto la derecha de países como Chile (Durán et al., 2020) o Estados Unidos (Goldberg, 2020), como los gobiernos antidemocráticos de países como Rusia o Filipinas, entre muchos otros (Bradshaw y Howard, 2017), la han usado ampliamente, mezclándola con otros repertorios y tecnologías. 
Esta podría ser una de las razones de la acusación contra las redes sociales y los troles de constituir un peligro para la democracia. No parece ser el caso. El alegato contra las fake news, donde se engloban las prácticas de difusión de información falsa a través de diversos medios, incluyendo los ejércitos de troles, también ha sido un tema común para comentaristas y figuras públicas. No obstante, dicha queja está enmarcada en otro tipo de análisis, sin mención de cuestiones tales como el "dogmatismo de los que se creen dueños de la verdad" o la "demonización del adversario" que se denuncia respecto de los troles orgánicos. Parece más probable que aquello que los comentaristas interpretan como las campanadas que anuncian el desmoronamiento de la democracia liberal tenga relación con las propiedades heterogéneas de las plataformas de internet, la confluencia y consolidación de contrapúblicos que estas han facilitado, y la promesa igualitarista a la que los individuos se sienten llamados (aunque sea fantasiosa). Asimismo, con la amenaza implícita de una creciente subjetivación y la posibilidad del establecimiento de una esfera pública sustantiva en oposición a la esfera pública ideal, burguesa, homogénea y orientada exclusivamente al "bien común".

Podríamos decir que se trata del viejo temor al barullo, a la incertidumbre, que muestran especialmente las élites del poder (Mills, 1987) ante cualquier configuración de las cosas, reparto de lo sensible, donde ellos no conserven una parte privilegiada. Como señala Mills (1987), los miembros de la élite reconocen su posición social y sus acciones colectivas están dirigidas a la mantención de dicho orden. Uno de los aspectos que distingue a la élite contemporánea de otras castas gobernantes es el rol que en la mantención de su poder han jugado los medios de comunicación de masas y el control de la información. Las plataformas mediáticas de la actualidad ponen en entredicho la estabilidad de las masas y amenazan con la emergencia de una comunidad de públicos (Mills, 1987, p. 283) o contrapúblicos (Fraser, 1999), ya que alteran la proporción entre hablantes y oyentes, así como las normas informales que regulan quién puede hablar, cuándo y durante cuánto tiempo; la relación entre la formación de opinión y su realización en acción social; y el grado de intromisión de la autoridad en la comunicación pública y en la autonomía con la que se forman las opiniones. Y si la manifestación de este temor se dirige con especial energía contra el troleo es porque, en cuanto práctica política, es donde de forma más patente y pública se ofrece este barullo o amenaza en ciernes, la falta de reverencia ante aquellos que pretenden encarnar el bien común, "la afirmación de la ausencia de fundamento del poder" (Rancière, 2011). Con su capacidad de constituir una estratagema subversiva que desenmascara lo que hay bajo la superficie de dichas pretensiones y que persigue desplazar los marcos impuestos para deliberación, el troleo es un objeto ominoso para las élites. 


\section{INTERPELAR O DISPERSAR}

Hemos buscado situar el troleo dentro del esquema de las prácticas políticas y lo hemos definido como una estratagema caracterizada por provocar y manipular al adversario para conseguir desplazar el marco discursivo impuesto. El sentido de esta estratagema es establecer un litigio a partir de la oposición de nuevos términos que permitan disputar el reparto de lo real o sensible. Para caracterizar el troleo en estos términos, además de delimitar sus aspectos constitutivos en cuanto acción comunicativa, procedimos a separarlo de una subcultura, momento, plataforma o tecnología específica. Para ello nos servimos de un ejemplo de la vida de Marx como polemista político.

Los troles pueden ser molestos, ofensivos, usar un lenguaje sucio, decir mentiras, llevar a cabo un sinnúmero de falacias (particularmente frecuentes son los argumentos ad hominem), entre otras atrocidades retóricas. También pueden ser extremadamente divertidos o, intentando serlo, ser extremadamente aburridos. Probablemente por todo aquello que hacen los troles cuesta tomar en serio al troleo.

Por ello, es necesario insistir en que lo que se ha buscado en este artículo es caracterizar al troleo y no al trol, cualesquiera que sean sus motivaciones psicológicas. El troleo como práctica política puede ser una práctica emancipatoria. La emancipación o libertad es aquello que constituye el sentido de la política. Como señala Arendt (1997, p. 69), la libertad puede ser "comprendida negativamente como no ser dominado y no dominar, y positivamente como un espacio solo establecible por muchos, en que cada cual se mueva entre iguales. Sin tales otros, que son mis iguales, no hay libertad". 0 , desde otra perspectiva, siguiendo nuevamente a Rancière (2006), que a su vez se apoya en Aristóteles, libertad es "tener parte en el hecho de mandar y ser mandado". El troleo como una práctica política se encontraría inscrito en esta concepción de la libertad, la de poder o no obedecer normas diferentes a las que me he impuesto a mí mismo. Esta es una teoría que tiende a ensanchar el poder colectivo, la democracia, en oposición a la teoría de la libertad como la facultad de realizar ciertas acciones sin ser impedido por la sociedad o el Estado, la teoría liberal clásica, cuyo efecto es restringir el poder colectivo (Bobbio, 2009). La libertad jurídica y autonomía política implícita en la estratagema del troleo no presupone que mis actos no deban perjudicar a nadie. La práctica de troleo encierra, por el contrario, la distinción entre amigo y enemigo (Schmitt, 2006), así como la de un "nosotros" constitutivo de una comunidad política que afronta la legítima existencia de un adversario con derecho a defender sus ideas en una oposición agonal (Mouffe, 1999, p. 16): "El enfrentamiento agonal, lejos de representar un peligro para la democracia, es en realidad su condición misma de existencia".

Así, no existe el troleo sin la aceptación tácita del derecho del adversario. Esto no implica que no existan casos en que el troleo pueda ser "nocivo" para la democracia (lo que queda demostrado por el uso de la estratagema por parte de contrapúblicos 
antidemocráticos), sino que el troleo como práctica política no sería constitutivamente antidemocrático, porque la democracia, en el sentido aportado por Mouffe (1999), sería uno de los requisitos de su realización.

El propósito de este ensayo no es defender al troleo como una práctica que se pueda privilegiar en el debate político. Los troles, independientemente de sus agendas, pueden ser perjudiciales dentro de algunas comunidades (Cheng et al., 2017). Pero tampoco pretendemos valorar el fenómeno en términos éticos. La intención de este texto es situar el troleo en el espacio de la esfera pública, describirlo en términos de sus usos, posibilidades y relaciones, y aproximarnos a criterios que nos permitan juzgarlo como una práctica, no como una misteriosa entidad u organización, ni como otras acciones o costumbres de la sociedad en línea, sin restarle importancia. Explorar una de las maneras en que un espacio habitualmente descrito como de mera circulación puede configurarse en un espacio de manifestación de un sujeto. Rescatando la analogía de Rancière (2006), interpelar al manifestante, no dispersar la manifestación.

La intervención policial en el espacio público no consiste, primero, en interpelar a los manifestantes, sino en dispersar las manifestaciones. [...] La policía dice que no hay nada que mirar en una calzada, nada que hacer, salvo circular. Dice que el espacio de circulación solo es espacio de circulación. La política consiste en transformar este espacio de circulación en espacio de manifestación de un sujeto. (p. 71)

\section{REFERENCIAS}

Anti Troll FAQ. (3 de noviembre del 2002). http://www.hyphenologist.co.uk/killfile/anti\_ trollı_faq.htm

Arendt, H. (1997). ¿Qué es la política? Paidós.

Bartlett, J. (2016). The dark net. Inside the digital underworld. Melville House.

Bishop, J. (2014). Representations of "trolls" in mass media communication: a review of media-texts and moral panics relating to "internet trolling". International Journal of Web Based Communities, 10(1), 7-24.

Bobbio, N. (2009). Teoría general de la política (Trads. A. de Cabo y G. Pisarello). Trotta.

Bradshaw, S., y Howard, P. N. (2017). Troops, trolls and troublemakers: a global inventory of organized social media manipulation [working paper]. https://comprop.oii. ox.ac.uk/research/troops-trolls-and-trouble-makers-a-global-inventory-oforganized-social-media-manipulation/

Bu, Z., Xia, Z., y Wang, J. (2013). A sock puppet detection algorithm on virtual spaces. Knowledge-Based Systems, 37(January), 366-377. doi:10.1016/j. knosys.2012.08.016 
Butler, J. (2002). What is a critique. An essay on Foucault's virtue. En D. Ingram (Ed.), The political (pp. 212-228). Blackwell.

Calvo, E., y Aruguete, N. (2020). Fake news, trolls y otros encantos. Cómo funcionan (para bien y para mal) las redes sociales. Siglo Veintiuno Editores.

Certeau, M. de. (2013). The practice of everyday life. University of California Press.

Cheng, J., Bernstein, M., Danescu-Niculescu-Mizil, C., y Leskovec, J. (2017). Anyone can become a troll: causes of trolling behavior in online discussions. En Proceedings of the 2017 ACM Conference on Computer Supported Cooperative Work and Social Computing (pp. 1217-1230). https://doi.org/10.1145/2998181.2998213

Coleman, G. (2012). Phreaks, hackers, and trolls and the politics of transgression and spectacle. En M. Mandiberg (Ed.), The social media reader (pp. 99-119). Nueva York University Press.

Donath, J. (1999). Identity and deception in the virtual community. En M. A. Smith y P. Kollock (Eds.), Communities in cyberspace (pp. 27-57). Routledge.

Durán, P., Lawrence, T., y Fernández, J. E. (17 de octubre del 2020). La red social Twitter y el proceso constituyente: el caso de las cuentas anómalas. CIPER. https://www. ciperchile.cl/2020/10/17/la-red-social-twitter-y-el-proceso-constituyente-elcaso-de-las-cuentas-anomalas/

Elliott, R. C. (7 de febrero del 2019). Satire. En Encyclopedia Britannica. https://www. britannica.com/art/satire

Encyclopedia Dramatica. (s. f.). En Wikipedia. https://en.wikipedia.org/wiki/Encyclopedia_ Dramatica

Estrada Saavedra, M. (2003). ¿Acción o práctica política? Notas en torno a un programa de investigación sobre la distinción conceptual entre lo social y lo político. Estudios Sociológicos, 21(1), 191-200. https://www.redalyc.org/articulo.oa?id=59806108

Fraser, N. (1999). Repensando la esfera pública: una contribución a la crítica de la democracia actualmente existente. Ecuador Debate. Opinión Pública, 46, 139-174.

Friedrich Wilhelm IV. (s. f.). En Wikipedia. https://de.wikipedia.org/wiki/Friedrich_ Wilhelm_IV

Goffman, E. (1959). The presentation of self in everyday life. Doubleday.

Goldberg, G. (24 de marzo del 2020). Dumping, astroturfing and trolling. https:// geoffgolberg.medium.com/dumping-astroturfing-and-trolling-2d9aa68b9ba3

Habermas, J., Lennox, S., y Lennox, F. (1974). The public sphere: an encyclopedia article (1964). New German Critique, (3), 49-55. doi:10.2307/487737 
Hardaker, C. (2010). Trolling in asynchronous computer-mediated communication: from user discussions to academic definitions. Journal of Politeness Research, 6(2), 215-242. doi:10.1515/jplr.2010.011

Howard, P. N. (2020). Lie machines: how to save democracy from troll armies, deceitful robots, junk news operations, and political operatives. Yale University Press.

Keller, F., Schoch, D., Stier, S., y Yang, J. (2017). How to manipulate social media: analyzing political astroturfing using ground truth data from South Korea. En Proceedings of the 11th International AAAI Conference on Web and Social Media, ICWSM 2017 (pp. 564-567). AAAI Press.

Kovic, M., Rauchfleisch, A., Sele, M., y Caspar, C. (2018). Digital astroturfing in politics: definition, typology, and countermeasures. Studies in Communication Sciences, 18(1), 69-85. https://doi.org/10.24434/j.scoms.2018.01.005

Linvill, D. L., y Warren, P. L. (2020). Troll factories: manufacturing specialized disinformation on Twitter. Political Communication, 37(4), 447-467. https://doi. org/10.1080/10584609.2020.1718257

Marx, K. (1844). Illustrations of the latest exercise in cabinet style of Frederick William IV. En Militant Archive. https://wikirouge.net/texts/en/Illustrations \_of $\backslash$ thel_Latest $\_$

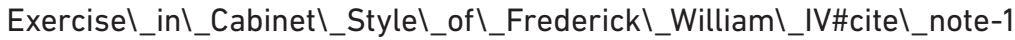

Merriam-Webster. (s. f.). Trolling. En Merriam-Webster.com dictironary. https://www. merriam-webster.com/dictionary/trolling

Mills, C. W. (1987). La élite del poder. Fondo de Cultura Económica.

Montes, L. (11 de junio del 2020). Reflexiones para los en-redados. El Mercurio, p. 3.

Montes, R. (7 de febrero del 2020). Ascanio Cavallo: “Las redes sociales están cumpliendo un papel fascista". Diario Financiero, pp. 16-17.

Mouffe, C. (1999). El retorno de lo político. Comunidad, ciudadanía, pluralismo, democracia radical. Paidós.

Mylonas, Y., y Kompatsiaris, P. (2019). Trolling as transgression: subversive affirmations against neoliberal austerity. International Journal of Cultural Studies, 24(1), 34-55.

Papacharissi, Z. (2005). The real/virtual dichotomy in online interaction: a meta-analysis of research on new media uses and consequences. Communication Yearbook, 29, 215-238. doi:10.1080/23808985.2005.11679048

Phillips, W. (2015). This is why we can't have nice things. Mapping the relationship between online trolling and mainstream culture. The MIT Press. 
Rancière, J. (2006). Política, policía, democracia (Ed. I. Trujillo; Trad. M. E. Tijoux; 1. ${ }^{\text {a ed. en }}$ Chile). LOM Ediciones.

Rancière, J. (2011). El tiempo de la igualdad. Diálogos sobre política y estética. Herder.

Romero, J. (27 de agosto del 2018). Habla el universitario acusado de amenazar a Cecilia Pérez: "Para mí esto es un show mediático, es absurdo y no tiene ninguna base legal". The Clinic. https://www.theclinic.cl/2018/08/27/ habla-el-universitario-acusado-de-amenazar-a-cecilia-perez-para-mi-estoes-un-show-mediatico-es-absurdo-y-no-tiene-ninguna-base-legal/

Roth, K. (2020). La amenaza global de China para los derechos humanos. En Human Rights Watch (Org.), Human Rights Watch World Report 2020: Events of 2019. https://www. hrw.org/es/world-report/2020

Schmitt, C. (2006). El concepto de lo político. Texto de 1932 con un prólogo y tres corolarios. Alianza Editorial.

Shaffer, K. (2019). Data versus democracy. How big data algorithms shape opinions and alter the course of history. Apress.

Smith, M. A., y Kollock, P. (Eds.). (1999). Communities in cyberspace. Routledge.

Terradas Saborit, I. (1992). Eliza Kendall. Reflexiones sobre una antibiografía. Servei de Publicacions de la Universitat Autònoma de Barcelona.

Warnken, C. (18 de junio del 2020). La epidemia de la intolerancia. El Mercurio, p. 3.

Wheen, F. (2018). Karl Marx. La biografía (Trad. R. Fontes Muñoz). Debate.

Zelenkauskaite, A., y Niezgoda, B. (2017). "Stop Kremlin trolls:" ideological trolling as calling out, rebuttal, and reactions on online news portal commenting. First Monday, 22(5). https://doi.org/10.5210/fm.v22i5.7795 